\title{
Jogos e brincadeiras: tempos, espaços e diversidades, de Tizuko Morchida Kishimoto e Maria Walburga dos Santos (Orgs.).
}

São Paulo: Cortez, 2016, 216 p.

\author{
Ligia de Carvalho Abóes Vercelli \\ Doutora e mestre em educação. Professora do Programa de Mestrado em Gestáo e Práticas Educacionais \\ da Universidade Nove de Julho (Progepe/Uninove). \\ ligia@uniq.pro.br
}

Como pesquisadora de formação de professores, práticas pedagógicas e políticas públicas referentes à educação infantil, minha preocupação está voltada às atividades desenvolvidas nas escolas da infância, uma vez que pesquisas recentes têm apontado que principalmente as crianças de $4 \mathrm{e}$ 5 anos têm sido colocadas em situação de escolarização em detrimento da principal atividade para essa faixa etária, a lúdica.

Diante desse cenário, tenho pesquisado artigos, livros, teses e dissertações que abordam a temática e, nessa busca, deparei com a presente obra. $\mathrm{Na}$ apresentação, Tizuko Morchida Kishimoto ressalta que o livro é resultado de pesquisas realizadas por alunos de pós-graduação que frequentaram as linhas de pesquisa Psicologia e Educação e História e Historiografia na Faculdade de Educação da Universidade de Sáo Paulo (FE-USP) e defenderam dissertaçôes e teses no período de 2000 a 2010 , além de outras investigaçōes sobre ludicidade, sob sua orientação. O livro também traz orientaçôes acadêmicas da autora realizadas em Portugal, na Universidade do Minho, em colaboração com a professora Júlia Oliveira-Formosinho, parceria iniciada em 1996 e que perdura até os dias atuais. Outros estudos que compóem a obra também foram produzidos no Grupo de Pesquisa: Contextos Integrados de Educação Infantil, coordenado pelas professoras Tizuko Morchida Kishimoto e Mônica Appezzato Pinazza.

O prefácio, escrito pelo professor João Amado, da Universidade de Coimbra, ressalta a relevância do livro e seu mérito, não somente para pesquisadores e professores, mas também e principalmente para pais e políticos, tendo em vista que os textos apontam para o direito que as crianças 
têm de brincar. A obra está dividida em dez capítulos, sendo que cada um deles foi escrito por diferentes autores.

No primeiro capítulo, intitulado Pesquisas sobre brinquedo no inicio do século XX, Tizuko Morchida Kishimoto discorre sobre duas pesquisas quantitativas a respeito da preferência por brinquedos realizadas nas cidades de Belo Horizonte e de São Paulo, no início do século XX, e aponta a escassez dessa modalidade de pesquisa no campo da educação. A primeira pesquisa, conduzida por Helena Antipoff, psicóloga educacional, na cidade de Belo Horizonte, em I929, contou com o apoio das alunas da Escola de Aperfeiçoamento, que tinha por objetivo formar professoras primárias para atuarem no contexto da educação mineira. Para a realização do estudo à época, Antipoff utilizou-se de um questionário contendo dez questôes, aplicado em 760 crianças de Io a I4 anos. Kishimoto apresenta os resultados referentes somente às questôes sobre a preferência dos brinquedos e o que as crianças gostariam de receber como presente de aniversário. A segunda pesquisa descrita foi realizada na cidade de São Paulo pela professora Noemy da Silveira Rudolfer, no Laboratório de Psicologia do Instituto de Educação, em I934, com o objetivo de investigar os jogos escolares preferidos pelas crianças dos segundos, terceiros e quartos anos das escolas primárias de Sáo Paulo. O interessante desse capítulo é perceber que Antipoff e Rudolfer, no final da década de 1920 e início da de 1930, entendiam a criança como um ser que tem voz, uma vez que as perguntas foram direcionadas a elas, concepção de criança ainda distante da defendida na ocasião.

Em Felicidade guerreira: brincar no quilombo, segundo capítulo da obra, Maria Walburga dos Santos articula, no campo da História da Educação, duas questôes atuais, uma voltada à constituição dos quilombos contemporâneos, apresentando um breve histórico dos quilombos no Brasil e a comunidade Bombas, universo da pesquisa, situada no Vale do Ribeira, e como tem se constituído como quilombola. A segunda questão se refere ao lúdico, ao brincar na referida comunidade, apresentando as formas de brincar entre as pessoas na comunidade e no interior da escola. Para responder a segunda questão a autora utilizou-se de uma pesquisa etnográfica pautada nas seguintes categorias: lúdico, jogos e brincadeiras, brinquedos e situaçóes lúdicas. Para cada categoria apresenta quadros seguidos das respectivas análises. 
No terceiro capítulo, intitulado Jogos de tabuleiro: análise na perspectiva histórica, Lila Cristina Guimarães Vanzella analisa jogos de tabuleiro em sua materialidade e imaterialidade..A autora apresenta várias definiçóes de jogo sob a ótica de diferentes autores: aponta a origem dos jogos na perspectiva de D. Alfonso X (In Luandd, I988) e Pennick (I992), sua materialidade e imaterialidade, e analisa os jogos "Serpentes e Escadas", "MokshaPatamu" (ou "ParamaPadaSopanam") e Escadas e Escorregadores em suas diferentes versóes.

Em O lúdico na época de Anchieta, quarto capítulo da obra, Maria Ephigênia de Andrade Cáceres Nogueira pesquisa o universo lúdico na época de Anchieta. Destaca que, pela ausência de material sobre a temática nessa época, recorreu aos documentos da Companhia de Jesus, os quais continham escritos sobre a criança no Brasil. Portanto, a autora apresenta a história de sua fundação, a história da igreja e da importância da cultura europeia católica no Renascimento e sua influência sobre a colonizaçáo portuguesa no Brasil. Várias foram as perguntas norteadoras da pesquisa, entre elas: Como os jesuítas enxergavam as crianças indígenas e suas brincadeiras? Teria sido a pedagogia jesuítica a mesma, quanto aos jogos e brincadeiras, no Brasil, em Portugal e nas outras partes do mundo onde eles mantinham colégios? Para responder aos questionamentos a autora fez uso da pesquisa de natureza histórica e, como procedimentos de coleta de dados, utilizou cartas jesuíticas, gravuras e escritos de viajantes e quadros de alguns pintores.

Lucia Maria Salgado dos Santos Lombardi, no quinto capítulo, O brincar na formação inicial de pedagogos, apresenta o resultado de sua pesquisa de mestrado desenvolvida na Faculdade de Educação da Universidade de São Paulo (FEUSP) cujo objeto foi a formação lúdica de professores. Para a realização da pesquisa, Lombardi frequentou, no curso de Pedagogia dessa universidade, a disciplina Brinquedos e Brincadeiras na Educação Infantil, ministrada pela professora Tizuko Morchida Kishimoto. As 57 alunas que cursavam essa disciplina, à épo$\mathrm{ca}$, foram divididas em grupos para estudar a ludicidade sob a ótica dos seguintes autores: Piaget, Vygotsky, Wallon, Bruner, Gilles Brougère e Paulo Salles de Oliveira. Realizaram estágios nas escolas e, de volta à universidade, discutiram as seguintes categorias: o papel do educador de brincar junto; conceito de infância e seu reflexo no ensino; a cultura infantil; 
os saberes docentes em contexto; a integração teoria e prática propiciada pelo processo reflexivo. A autora ressalta o quanto o formador de futuros professores tem de estar imbuído de compromisso com a construção de saberes dos alunos fazendo a relação teoria e prática, para que eles possam, no chão da escola, perceber o sentido do que foi estudado. O capítulo é muito significativo por apontar o vai e vem das observaçóes realizadas pelas alunas no cotidiano escolar e as reflexôes sobre essas práticas, exercício esse, no nosso entendimento, fundamental para o trabalho docente.

Em Brincar: oportunidade lúdica nos tempos livre da criança?, sexto capítulo, Maria de Lourdes Gonçalves Machado Rocha apresenta uma pesquisa realizada em 5 jardins de infância localizados na periferia de um meio urbano, em Portugal, durante o prolongamento do horário $(\mathrm{PH})$, tidos como espaços de educaçáo informal. As crianças permanecem nesse espaço entre I 4 h3o e I 5 h. O objeto de estudo foi o tempo livre da criança e se sua maneira de brincar era livre ou espontânea, ou seja "[...] a conduta lúdica da criança que se exprime pela espontaneidade, prazer e liberdade na tomada de decisóes, por exemplo: jogos de movimento ou de faz de conta. O adulto não orienta a açấo [...]" (p. I64). Para a coleta de dados a autora utilizou-se da observação participante durante o $\mathrm{PH}$ e entrevistas com Io8 crianças de 4 e 5 anos de idade, educadores e animadores e questionários entregues aos pais, além de fotografias. A riqueza desse capítulo encontra-se nas falas das crianças que, infelizmente, são revestidas da proibição da expressão infantil por parte dos adultos.

Tania Maria Cordeiro de Azevedo, no sétimo capítulo, intitulado Brinquedos e gênero na educação infantil: estudo etnográfico, traz o resultado de sua tese de doutorado defendida em 2003 na FEUSP. O universo de estudo foi uma unidade de educação infantil localizada em Niterói/ RJ, no qual se buscou identificar, numa perspectiva foucaultiana, as maneiras pelas quais as representaçóes de gênero são produzidas por meio dos brinquedos e brincadeiras de crianças de o a 6 anos. A autora inicia o capítulo conceituando gênero e como a escola reproduz as diferenças de gênero no currículo. Também apresenta pesquisas desenvolvidas no Brasil e em outros países tais como Espanha, França e Austrália, apontando que em todos eles as representaçóes sociais sobre gênero são reforçadas pelos professores nas escolas. $\mathrm{Na}$ escola pesquisada, as brincadeiras de casinha e com bonecas são direcionadas às meninas; futebol, bonecos de super- 
heróis e competição, aos meninos. Dessa forma, a escola disciplina os corpos e os meninos exercem controle sobre as meninas. A autora observou também que a própria professora fez distinção de gênero em diferentes situaçôes. Entendemos a urgência de a escola rever essa questão, uma vez que os brinquedos e as brincadeiras náo têm sexo.

No oitavo capítulo, intitulado O lúdico e a emergência da literacia em creche, Graça Bandola Cardoso apresenta o resultado de sua pesquisa de doutorado concluída em 20I2, na Universidade do Minho. Vale lembrar que o termo "literacia" é sinônimo de letramento. O universo do estudo foi um Centro Comunitário de uma pequena localidade no norte de Portugal que, à época da pesquisa, situava-se numa perspectiva pedagógica de cunho tradicional. As atividades eram selecionadas pelo professor sem que a criança pudesse opinar e participar. As questóes referentes ao letramento também eram ausentes das preocupaçóes dos adultos e os livros ficavam fora do alcance das crianças. Não havia, nas salas da creche, qualquer alusão à escrita. A intervenção realizada pela autora implicou no aprofundamento de referenciais socioconstrutivistas, os quais admitem a participaçáo da criança. Com isso, as práticas pedagógicas as envolviam e lhes davam possibilidades de entrar no mundo da leitura e da escrita. O capítulo aponta para a possibilidade de se trabalhar a leitura e a escrita desde a mais tenra infância e traz fotografias das escritas realizadas pelos pequenos.

Maria do Carmo Monteiro Kobayashi e Letícia Sayuri Morinishi, no nono capítulo, intitulado Mukashi banashi: narrativas antigas japonesas e transmissão cultural, abordam a literatura infantil e oriental, focando nas narrativas japonesas Mukashi banashi. As autoras buscaram responder à seguinte pergunta: Tais narrativas, propagadas oralmente de geração em geração com a vinda dos japoneses para o Brasil, no início do século XX, manteriam o processo de transmissão até os tempos atuais? $\mathrm{O}$ universo da pesquisa foi uma comunidade de descendência nipônica situada na cidade de Mogi das Cruzes/SP. Para tanto, as autoras fizeram um estudo sobre o surgimento dos Mukashi banashi no Japão, sua introdução no Brasil e como se deu a transmissão.

No último capítulo do livro, Classificaçôes de objetos lúdicos: sistema COL na brinquedoteca, Gilles Henrique Tavares de Azevedo, aluno de Iniciação Científica (IC), conceitua sistema de classificação, como 
ele ocorre com objetos lúdicos e como o sistema Classement des Objets Ludiques (COL), de origem francesa, comporta-se na brinquedoteca da FEUSP em seu processo de classificar, organizar e recuperar jogos e brinquedos. Azevedo apresenta a metodologia utilizada na pesquisa e explica como ocorrem as classificaçóes de objetos lúdicos. Traz autores que trabalham nessa perspectiva, porém se pauta na obra de Piaget. Além da classificação COL, o autor explica as classificaçóes ICCP e ESAR, respectivamente, Internacional Council for Childrens's Play e Exercice, Symbolique, Assemblage e Règles.

Trata-se de uma leitura muito instigante para todos os educadores, principalmente aqueles que lecionam para crianças pequenas ou formam professores para a educaçáo infantil. A coletânea traz várias proposiçóes e questionamentos que nos levam a refletir sobre a importância da atividade lúdica na prática pedagógica, atividade fundamental para o desenvolvimento infantil. 